Research Article

\title{
Bearing Repair and Monitoring for Poyanghu Cable-Stayed Bridge
}

\author{
X. X. Cheng $(\mathbb{D}$, F. B. Ma, J. Q. Chen, B. Dong, and G. Wu \\ School of Civil Engineering, Southeast University, Nanjing, China \\ Correspondence should be addressed to X. X. Cheng; cxx_njut@hotmail.com
}

Received 25 July 2020; Revised 16 November 2020; Accepted 4 December 2020; Published 17 December 2020

Academic Editor: Evangelos J. Sapountzakis

Copyright (C) 2020 X. X. Cheng et al. This is an open access article distributed under the Creative Commons Attribution License, which permits unrestricted use, distribution, and reproduction in any medium, provided the original work is properly cited.

Currently, the bearings of Poyanghu Bridge, a 636-meter long cable-stayed bridge, have been damaged. According to numerical analyses, the mechanical state of the damaged bridge unfavorably deviates from the ideal design state, and the bridge should be repaired in time to restore its safety and serviceability. However, compared with the bearing repair of beam bridges, much less scientific and engineering endeavors have been made in the history to direct the bearing repair of cable-stayed bridges. This article proposes two innovative bearing repair schemes for cable-stayed bridges and reports the numerical validations, the on-location applications, and the monitoring of the proposed repair schemes under the engineering backgxround of Poyanghu Bridge. Through these works, it is found that the proposed repair schemes are effective in practical use.

\section{Introduction}

Bearing damages are usual structure diseases for bridges in operation. If they are not repaired in time, the health of the bridges could be endangered. For bearing repairs of beam bridges, the jack-up method is generally utilized. For jack-up practice to take place, the beam will be jacked up and rested on temporary bearings; after the damaged bearing is repaired, the beam will be reset. A lot of scientific research studies and engineering applications suggest that the jack-up technique is mature and applicable to bearing repairs of beam bridges [1-5]. Under operational loads and environmental corrosions, the bearing damages can also be detected on cable-stayed bridges. However, different from beam bridges, when the bearings on cable-stayed bridges fail, the main girders will be lifted up by the stayed cables near the damaged bearings, leading to the dangerous scenarios in which the main girders and the bearings are separated.

With regard to the mechanical states, cable-stayed bridges with bearing damages might be more unfavorable than beam bridges with bearing damages due to the complicated interactions among the stayed cables, the main girder, the damaged bearings, and the piers on the auxiliary pier-girder connecting regions of the cable-stayed bridges [6-12].
However, compared with the bearing repair of beam bridges, much less scientific research studies or engineering endeavors have been dedicated to the bearing repair of cable-stayed bridges to the writers' knowledge. In July, 2019, bearing damages were observed on Poyanghu Bridge, a 636-meter long cable-stayed bridge. To repair the bearings, two innovative repair schemes were proposed by practicing engineers, which are reported and numerically validated in this article. By comparing the two repair schemes, one of them was chosen and successfully implemented on the location by the repair personnel during September to October in 2019. This article also reports the on-location monitoring of the bearing repair of Poyanghu Cable-stayed Bridge. Different from monitoring of the bearing repair of beam bridges which generally focuses on the displacements of the beams near the bearings [13], the present monitoring practice measured the forces of some stayed cables in comparison with the calculated results from numerical models.

1.1. Engineering Background. Poyanghu Bridge is a longspan bridge on the highway from Jiujiang City to Jingdezhen (Figure 1). The total length of the bridge is $636 \mathrm{~m}$ with four spans $(65+123+318+130 \mathrm{~m})$. It is a prestressed concrete 


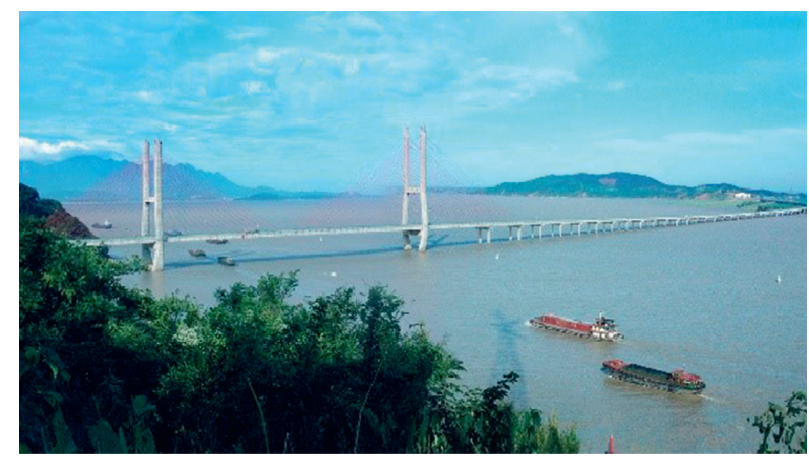

Figure 1: View of Poyanghu Bridge.

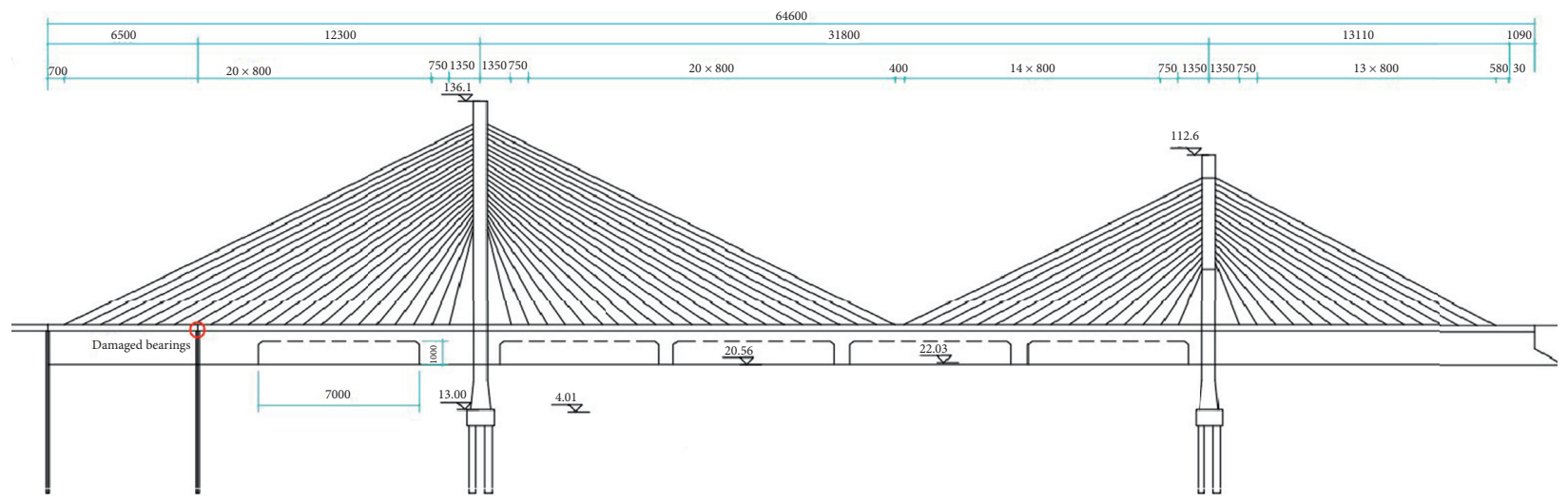

Figure 2: Elevation sketch of Poyanghu Bridge (unit: cm).

cable-stayed bridge with high and low pylons (Figure 2). The structure is a fundamental semifloating system with the main girder and the pylons separated. Bearings are arranged on the lower cross-beams of the pylons to support the main girder. In the side span of the high pylon, auxiliary piers are constructed with bearings arranged on top to support the main girder. The main girder cast in C55 concrete is $n$ shaped in cross section. The width of the main girder is $27.5 \mathrm{~m}$.

Poyanghu Bridge was constructed and opened to traffic in 2000. However, in July, 2019, its administrative staff detected damages in both the downstream side and the upstream side bearings arranged on top of the auxiliary piers. The damaged bearings of type QZL-3300-4200ZXS are spherical tension-compression type. Their tensile capacity is $3300 \mathrm{KN}$, and compressive capacity is $4200 \mathrm{KN}$. The size of the damaged bearings is $150 \mathrm{~cm} \times 112 \mathrm{~cm}$. The rotation angle limit is $0.02 \mathrm{rad}$, and the longitudinal and the transverse displacement limits are $\pm 15 \mathrm{~cm}$ and $\pm 2 \mathrm{~cm}$, respectively, for the bearings. The cross-section view of a bearing is shown in Figure 3. For the downstream side bearing, all anchoring bolts connecting the upper steel plate to the main girder fell off, and the main girder and the bearing were separated (Figure 4(a)). Besides, transverse displacement was observed for the main girder near the downstream side bearing. For the upstream side bearing, two anchoring bolts broke (Figure 4(b)). Based on engineering experiences, the administrative staff thought that the mechanical state of
Poyanghu Bridge was dangerous at that time. If the bearings were not repaired in time, the safety and the serviceability of the entire bridge might be endangered.

1.2. Repair Schemes. Two innovative repair schemes have been proposed by the practicing engineers for bearing repair of Poyanghu Cable-stayed Bridge, including one relying on the tensioning of the steel strands and the other one employing the temporary supports and the vehicle ballast. They are reported as follows.

1.2.1. Repair Scheme 1. Repair scheme 1 is a two-level repair plan, which relies on the tensioning of the steel strands. The $1^{\text {st }}$ level of repair is an emergency rescue practice, which utilizes the four $X$-shaped steel strands arranged near the bearings tensioned with $1000 \mathrm{kN}$ force each to rapidly strengthen the stability of the structure (Figure 5(a)). The $X$-shaped steel strands are attached to two 3.6 meter long steel channel members with the dimension shown in Figures 5(b) and 5(c) arranged on two sides of the bridge piers by planting reinforcing bars at the height of 1 meter below the capping beam. Therefore, the repair practice might cause the damage of the piers at the connections of $X$-shaped steels. $X$-shaped steel strands employed are PES5-85 type hot extrusion polyethylene sheath cables made of $855 \mathrm{~mm}$-in-diameter steel wires. Their cross section area is $16.69 \mathrm{~cm}^{2}$; their weight per unit length is $13.1 \mathrm{~kg} / \mathrm{m}$; their external diameter is $6.1 \mathrm{~cm}$; their 


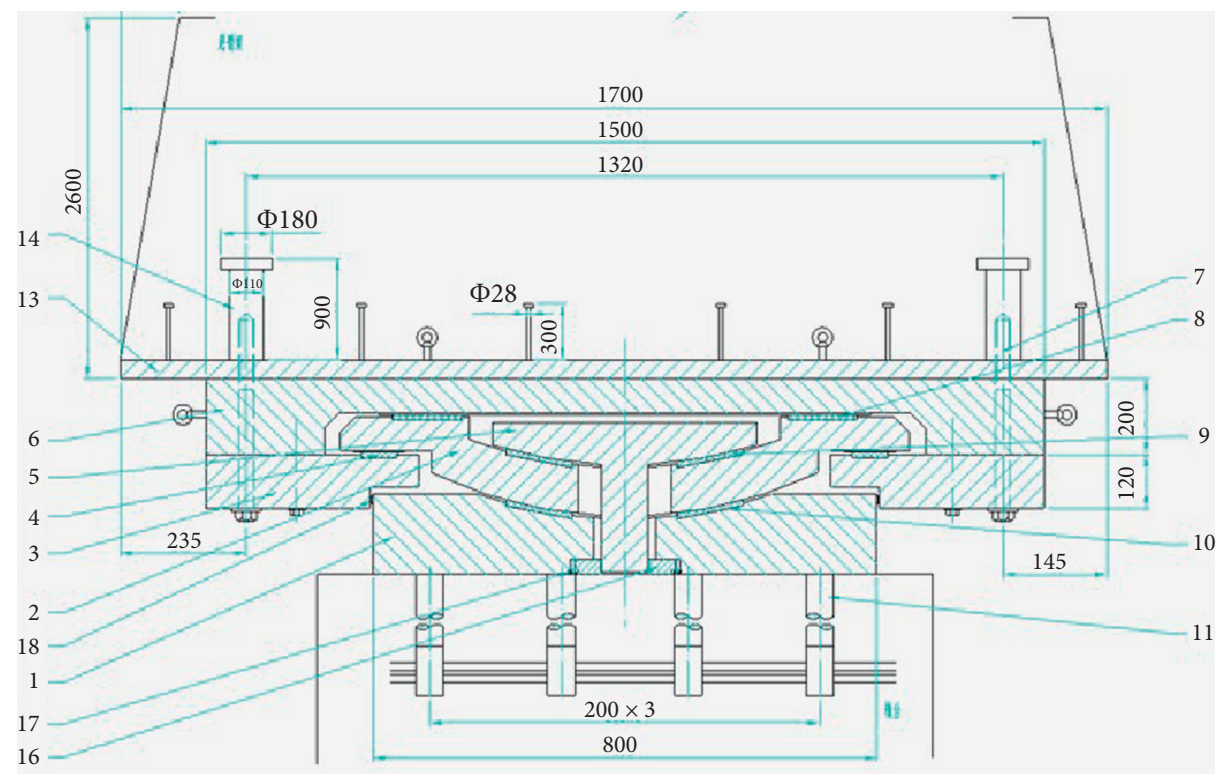

FIGURE 3: Details of the bearing (unit: $\mathrm{mm}$ ).

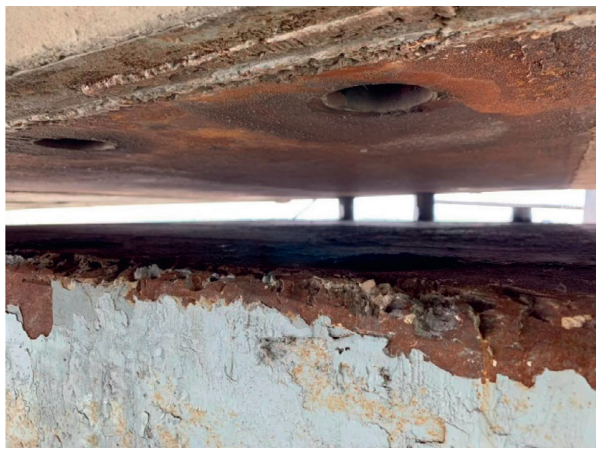

(a)

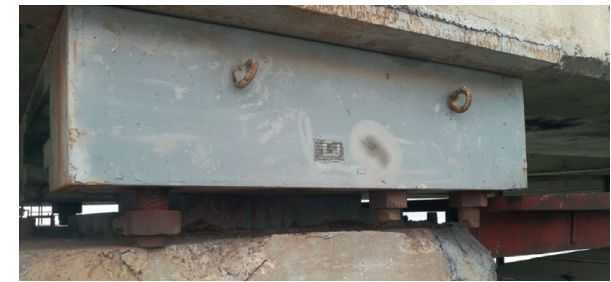

(b)

FIGURE 4: Damaged bearings: (a) downstream side bearing and (b) upstream side bearing.

breaking force is $2620 \mathrm{kN}$; and their strength is $1570 \mathrm{Mpa}$. The $2^{\text {nd }}$ level of repair is a repair practice in its true sense, which utilizes eight vertical steel strands tensioned with $2000 \mathrm{kN}$ force each to position correctly the main girder in relation to the bearings to facilitate the repair of the bearings (Figures 5(d) and 5(e)). The vertical steel strands employed are PES7-85 type hot extrusion polyethylene sheath cables made of $857 \mathrm{~mm}$-in-diameter steel wires. Their cross section area is $32.71 \mathrm{~cm}^{2}$; their weight per unit length is $25.7 \mathrm{~kg} / \mathrm{m}$; their external diameter is $8.3 \mathrm{~cm}$; their breaking force is $5136 \mathrm{kN}$; and their strength is $1570 \mathrm{Mpa}$.

1.2.2. Repair Scheme 2. Due to the feasibility and other considerations, another two-level repair plan (repair scheme 2) is also proposed by the practicing engineers. During the $1^{\text {st }}$ level of repair, two steel cylinders of $25 \mathrm{~cm}$ in diameter are arranged near each of the two damaged bearings as temporary supports so that emergency rescue can be realized (Figure 6(a)). During the $2^{\text {nd }}$ level of repair, after the bearings are repaired, a vehicle of around $25 \mathrm{kN}$ is utilized as ballast to adjust the position of the main girder to facilitate the tensioning of the anchoring bolts arranged between the main girder and the bearings (Figure 6(b)).

1.3. Numerical Simulations of the Repair Processes. To explore the effectiveness of the two repair schemes, the repair processes are simulated correspondingly on a commercial finite-element (FE) platform. Two FE models are established, including a simplified beam element model for the entire bridge and a detailed solid element model for the main girder section above the auxiliary piers. The beam element model can be utilized to study the mechanical behaviors of the entire bridge under multiple scenarios, while the solid element model can be used to explore the stress fields of the local position. By changing the boundary conditions and connections of the two FE models, four scenarios are simulated for Poyanghu Bridge during both of the two repair 


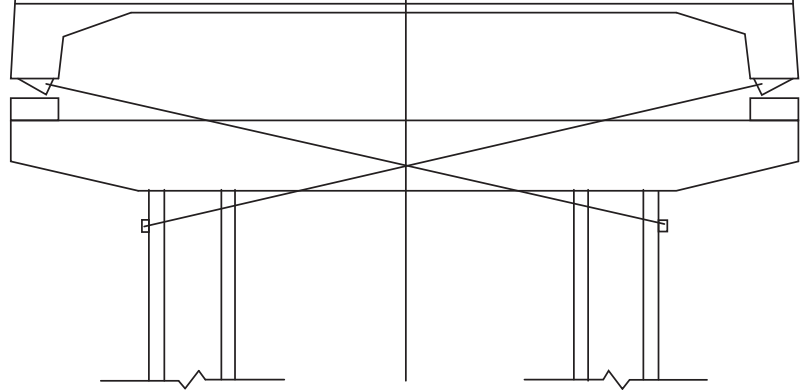

(a)

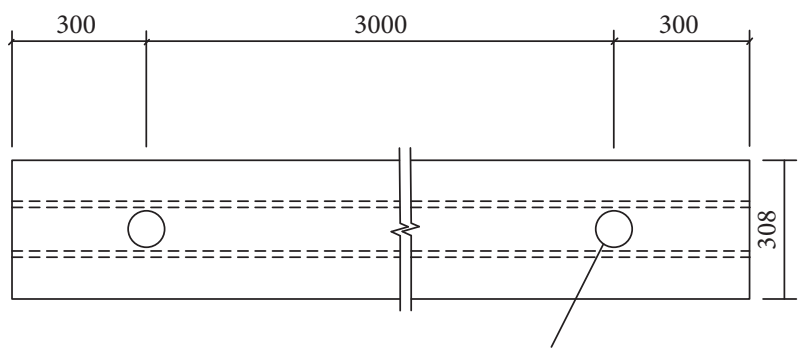

A connection of X-shaped steel strands

(c)

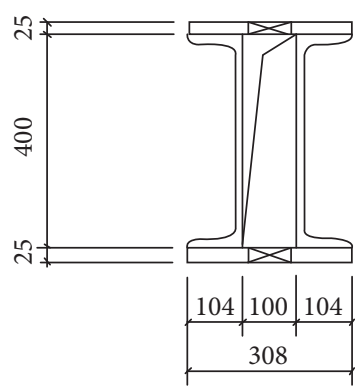

(b)

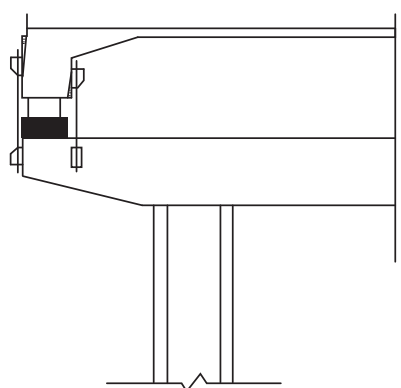

(d)

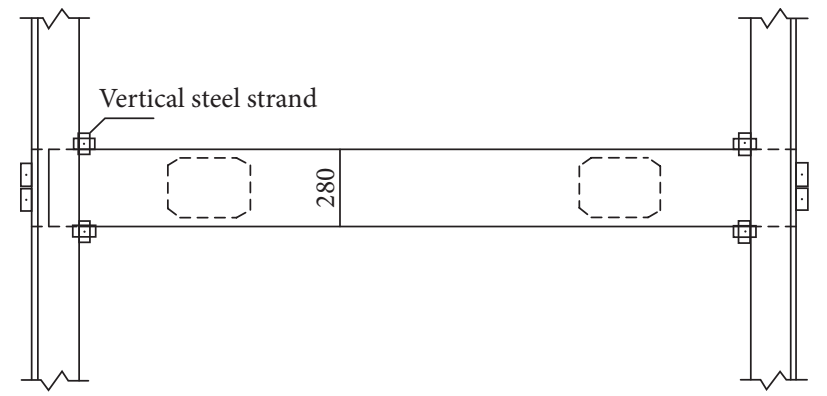

(e)

Figure 5: Sketches for repair scheme 1. (a) $1^{\text {st }}$ level repair (emergency rescue). (b) Cross section of steel channel members arranged on two sides of the bridge piers for fixing the $X$-shaped steel strands (unit: $\mathrm{mm}$ ). (c) Top view of steel channel members arranged on two sides of the bridge piers for fixing the $X$-shaped steel strands (unit: $\mathrm{mm}$ ). (d) $2^{\text {nd }}$ level repair (bearings repair). (e) Plan view of $2^{\text {nd }}$ level repair.

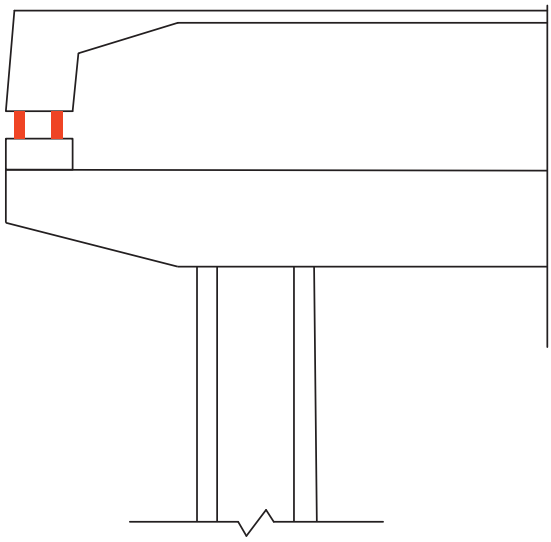

(a)

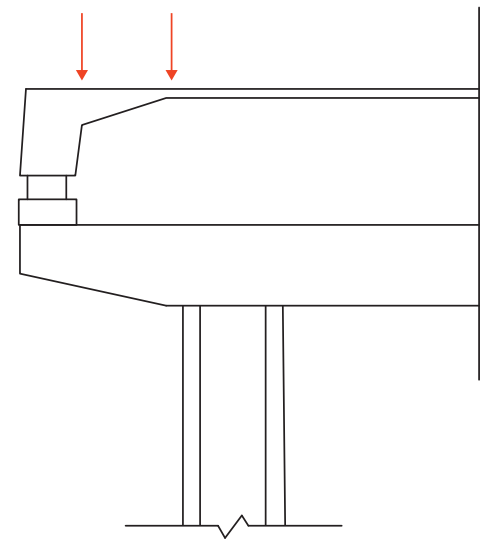

(b)

FIGURE 6: Sketches for repair scheme 2: (a) $1^{\text {st }}$ level repair (emergency rescue); (b) $2^{\text {nd }}$ level repair (bearings repair). 
processes, i.e., the damaged case, the emergency rescue case $\left(1^{\text {st }}\right.$ level of repair), the repair case ( $2^{\text {nd }}$ level of repair), and the intact case.

1.3.1. Numerical Models. The beam element model is established on MIDAS FE platform (Figure 7). The pylons and the main girder are modeled using 339 beam elements, and the stayed cables are modeled using 152 truss elements. The internal forces of the stayed cables are identified using the optimization module provided by MIDAS. For the intact case, the vertical displacements of the main girder at the $1 / 4$, $1 / 2$, and $3 / 4$ spans of the main span are regarded as the optimization targets. For the damaged case, the vertical displacements of the main girder and the transverse displacement of the main girder on top of the auxiliary piers are both regarded as the optimization targets. For the emergency rescue and the repair cases of repair scheme 1, the steel strands are modeled using truss elements, and the tensile forces are applied to the steel strands by using the initial tensile loads provided by MIDAS. For the emergency rescue case of repair scheme 2, the temporary supports are modeled using beam elements. For the repair case of repair scheme 2, the ballast on the main girder is simulated by the concentrated force.

The solid element model is established for the main girder section above the auxiliary piers on ANSYS FE platform using 12803 hexahedron elements (Figure 8). The numerical simulation process for the solid element model is of three steps: (1) extracting the displacements of related nodes from the computational results of the beam element model in different scenarios; (2) calculating the displacement distributions on the whole cross-sections of the solid element model using linear interpolations based on the plane-section assumption; and (3) calculating the wholefield stress responses of the solid element model in different scenarios by applying the displacement boundary conditions calculated in the previous step.

\subsubsection{Mechanical States of Poyanghu Bridge for Intact and} Damaged Cases. The beam element model is utilized to calculate the static mechanical states of Poyanghu Bridge under the dead load for the intact and the damaged cases. The displace responses, the stress distributions, and the cable force distributions calculated are shown in Figures 9-11, respectively. As shown in Figure 9, the surface of the main girder is smooth along the bridge for the intact case; for the damaged case, the main girder section above the auxiliary piers noticeably deflects upward on the downstream side, which adversely affects the driving safety for vehicles running along the bridge. In Figure 9(b), the displacements calculated at the damaged support from the numerical model are $5.31113 E-003 \mathrm{~m}, 2.50000 E-002 \mathrm{~m}$, and $7.33101 E-001 \mathrm{~m}$ for longitudinal, transverse, and vertical directions, respectively. They are with $15.96 \%, 19.09 \%$, and $1.26 \%$ relative errors compared with the values measured in the real site $(6.32 E-03 \mathrm{~m}, 3.09 E-02 \mathrm{~m}$, and $7.24 E-01 \mathrm{~m})$. According to Figure 10, after the bridge is damaged, the stress distribution on pylons and the main girder changes noticeably; the maximum compression stress increases, and the maximum tensile stress is amplified by an order of magnitude. According to Figure 11, after the bridge is damaged, the cable force distribution deviates from the ideal design state; the cable forces distributed nonuniformly at the side span of the high pylon, and the cable force changes significantly between neighbouring cables there. According to Figures 10 and 11, the calculated stresses for the pylons, the main girder, and the cables of the damaged bridge are fortunately within the strengths of these components. Although there is no serious safety issue for the time being, the stability of the entire bridge might still be endangered if the bearings were not repaired in time.

Besides, the dynamic characteristics of Poyanghu Bridge are also calculated using the beam element model for the intact and the damaged cases and shown in Figure 12. As can be seen, after the bridge is damaged, the low-order natural frequencies of the bridge decrease, possibly leading to stronger resonances of the bridge under strong winds. Besides, the mode shapes of Poyanghu Bridge in intact case can be clearly classified as vertical bend type (Figures 12(a) and 12(g)) or torsion type (Figures 12(c), 12(e), and 12(i)); however, the mode shapes of the bridge in damaged case usually feature complicated coupling between vertical bend and torsion (Figures 12(b), 12(d), 12(h), and 12(j)).

Both the static responses and the dynamic characteristics calculated using the simplified beam model suggest that the Poyanghu Bridge becomes unfavorable in safety and serviceability after the damage, and it must be repaired in time to avoid the structural failure and restore its serviceability. Similar results are obtained by using the solid element model to calculate the local stress field of the main girder section above the auxiliary piers in the damaged case. As shown in Figure 13, for the damaged case, stress concentrations can be observed on the corners of the main girder section. Besides, the maximum von Mises equivalent stress exceeds the material strength of C55 concrete, suggesting that local strength failures might be induced on the bridge in the damaged case.

\subsubsection{Mechanical States of Poyanghu Bridge for the Emer-} gency Rescue Cases. For both the repair scheme 1 and the repair scheme 2, the mechanical states of Poyanghu Bridge in emergency rescue cases under the dead loads are calculated. As shown in Figure 14, the displacement responses calculated for the two emergency rescue cases are close, and they are also close to the displacement response calculated for the damaged case (Figure 9(b)). Similar situations hold true for the stress distributions on pylons and the main girder (see Figures 15 and 10(b)) and the cable force distributions (see Figures 16 and 11(b)). Besides, the von Mises equivalent stress distributions on the main girder section calculated for the two emergency rescue cases (Figure 17) are both close to stress distribution calculated for the damaged case (Figure 13). These analyses suggest that the static mechanical state of the damaged Poyanghu Bridge is not improved by the emergency rescue for both the repair scheme 1 and the repair scheme 2. In addition, for the 


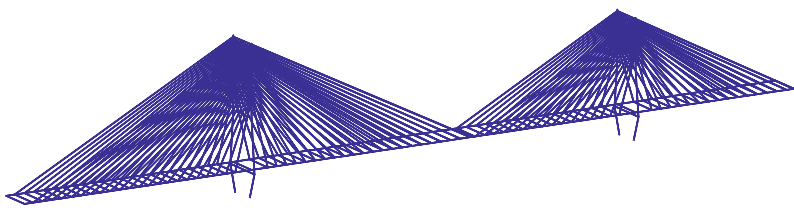

Figure 7: Simplified beam element model.

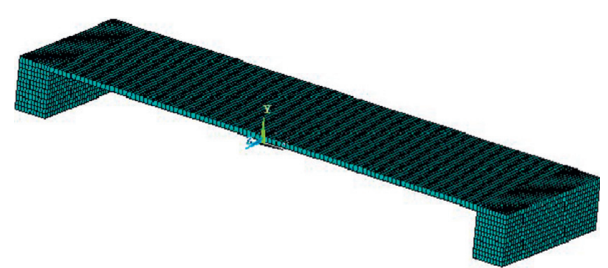

FIGURE 8: Detailed solid element model.

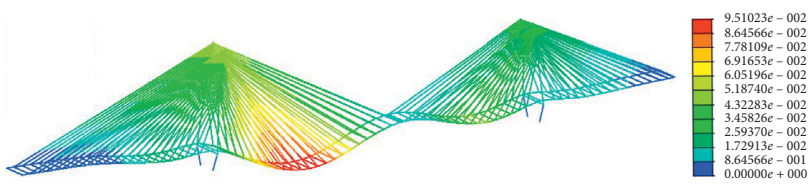

(a)

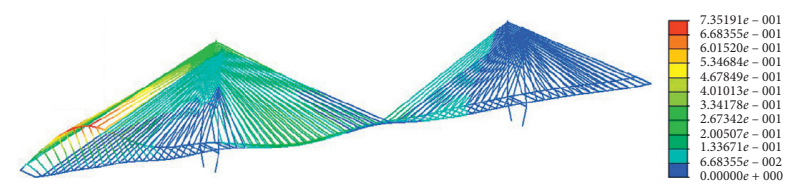

(b)

Figure 9: Displacement responses for (a) intact case and (b) damaged case (unit: $\mathrm{m}$ ).

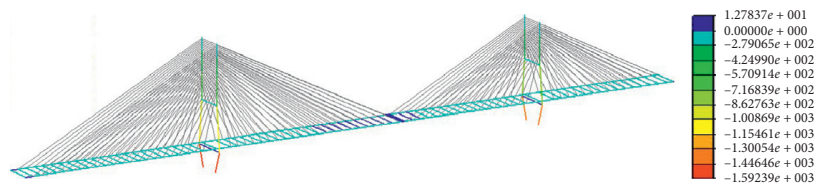

(a)

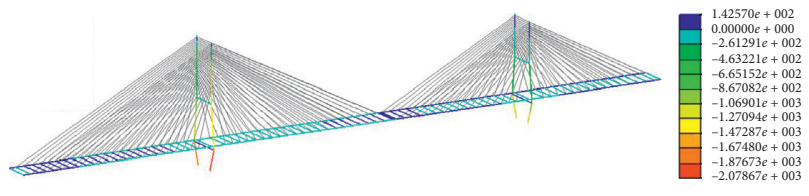

(b)

FIgURE 10: Stress distributions on pylons and the main girder for (a) intact case and (b) damaged case (unit: tonf $/ \mathrm{m}^{2}$ ).

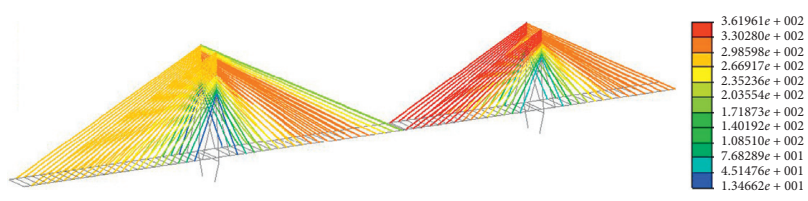

(a)

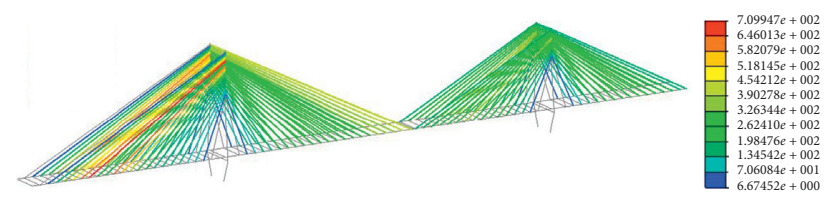

(b)

Figure 11: Cable force distributions for (a) intact case and (b) damaged case (unit: tonf).

emergency rescue case of repair scheme 1 , the $X$-shaped steel strands utilized are attached to the two steel members arranged on the sides of the piers. Therefore, the safety of the piers in that case is additionally examined using a detailed FE model. As shown in Figures 17(c) and 17(d), von Mises stresses at some positions on the piers are slightly greater than the material strength, indicating the unfavorable local behaviors of the piers in emergency rescue case of repair scheme 1 .

However, the buckling analyses suggest that the emergency rescues are helpful for improving the stability of the bridge. As shown in Figure 18, for both the repair scheme 1 and the repair scheme 2 , the buckling eigenvalues of the entire bridge calculated for the emergency rescue cases increase to $1.25 \sim 1.5$ times the original values calculated for the damaged case. Besides, according to Figure 19, when the emergency rescue is undertaken on the damaged bridge, most low-order instability shapes change from unfavorable out-plane patterns to favorable in-plane patterns. These suggest that the purpose of the emergency rescues is to improve the spatial stability of the whole structure and guarantee the construction safety of the 


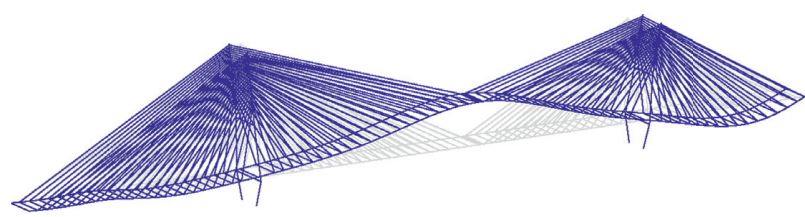

(a)

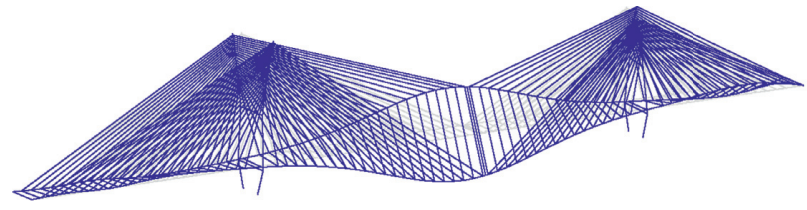

(c)

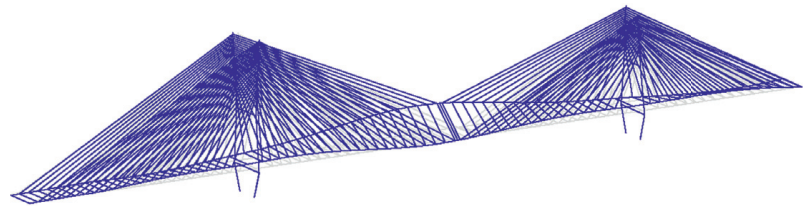

(e)

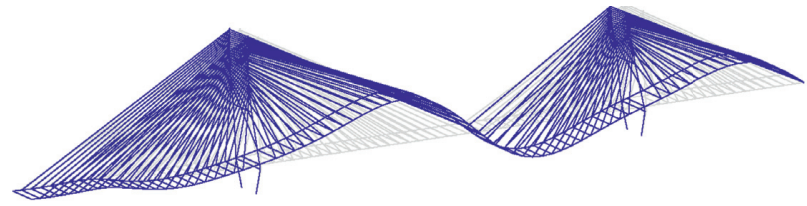

(g)

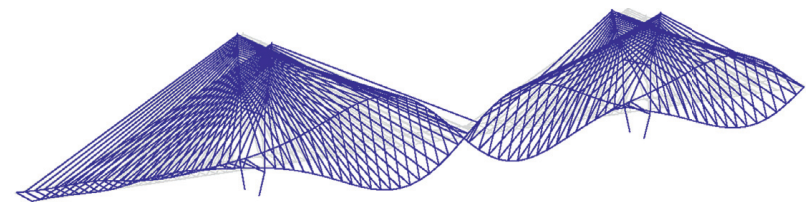

(i)

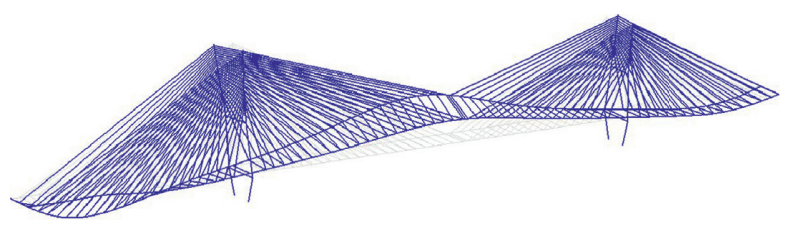

(b)

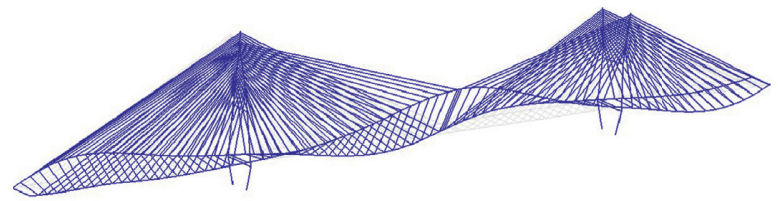

(d)

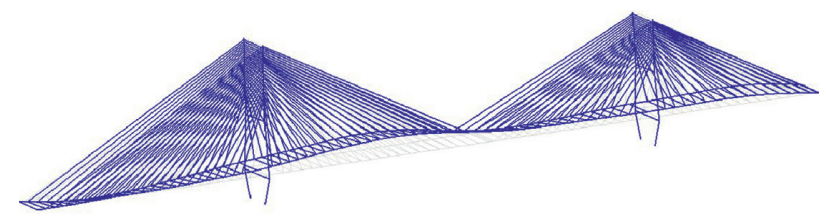

(f)

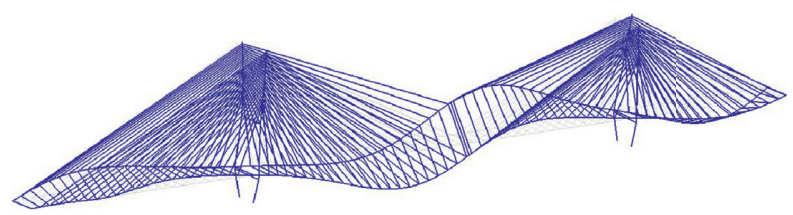

(h)

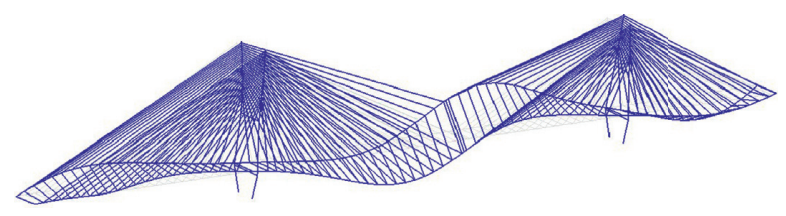

(j)

Figure 12: Mode shapes for intact and damaged cases. (a) $1^{\text {st }}$ mode for intact case $(1.13 \mathrm{~Hz})$. (b) $1^{\text {st }}$ mode for damaged case $(0.98 \mathrm{~Hz})$. (c) $2^{\text {nd }}$ mode for intact case $(1.44 \mathrm{~Hz})$. (d) $2^{\text {nd }}$ mode for damaged case $(1.33 \mathrm{~Hz})$. (e) $3^{\text {rd }}$ mode for intact case $(1.51 \mathrm{~Hz})$. (f) $3^{\text {rd }}$ mode for damaged case $(1.5 \mathrm{~Hz}) .(\mathrm{g}) 4^{\text {th }}$ mode for intact case $(1.67 \mathrm{~Hz})$. (h) $4^{\text {th }}$ mode for damaged case $(1.57 \mathrm{~Hz})$. (i) $5^{\text {th }}$ mode for intact case $(2.13 \mathrm{~Hz})$. (j) $5^{\text {th }}$ mode for damaged case $(1.94 \mathrm{~Hz})$.

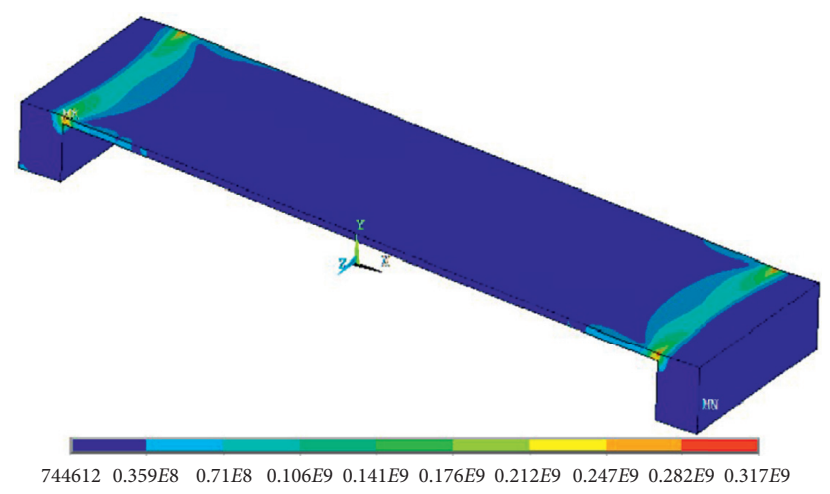

Figure 13: Von Mises equivalent stress distribution on the main girder section for the damaged case (unit: Pa).

subsequent repairs ( $2^{\text {nd }}$ level of repair), rather than to directly solve the strength and the stiffness problems with the damaged bridge.
1.3.4. Mechanical States of Poyanghu Bridge for the Repair Cases. Global and local mechanical states of Poyanghu Bridge in the repair cases are calculated using the numerical 


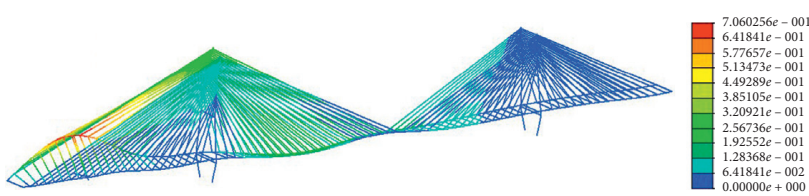

(a)

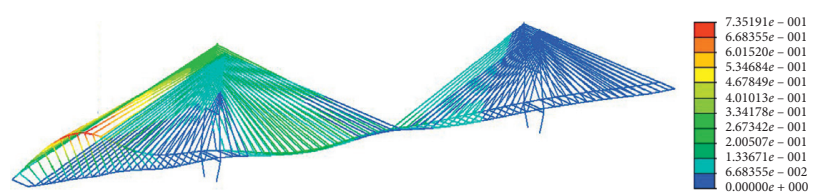

(b)

FIgURE 14: Displacement responses for the emergency rescue cases (unit: m): (a) repair scheme 1 and (b) repair scheme 2.

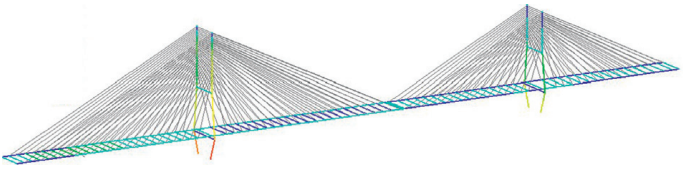

(a)

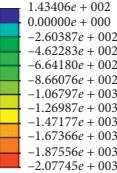

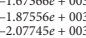

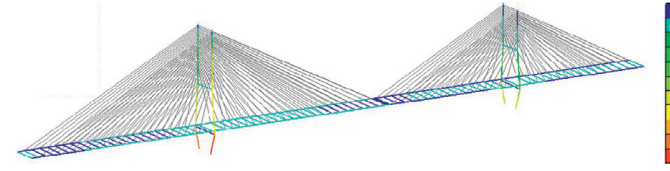

(b)

FIGURE 15: Stress distributions on pylons and the main girder for the emergency rescue cases (unit: tonf/ $\mathrm{m}^{2}$ ): (a) repair scheme 1 and (b) repair scheme 2 .

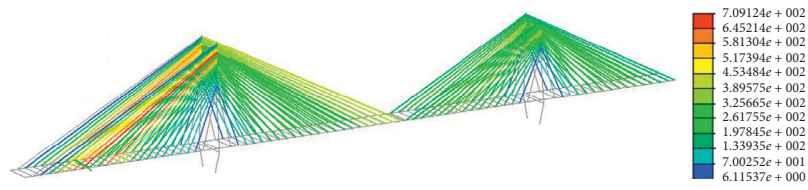

(a)

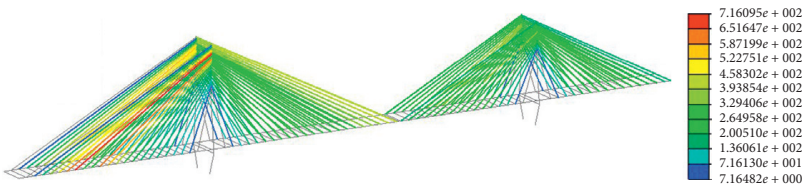

(b)

Figure 16: Cable force distributions for the emergency rescue cases (unit: tonf): (a) repair scheme 1 and (b) repair scheme 2.

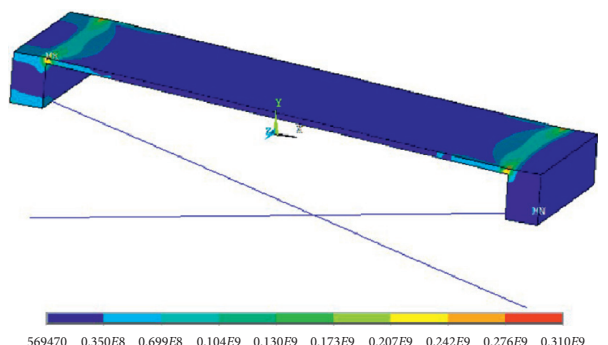

(a)

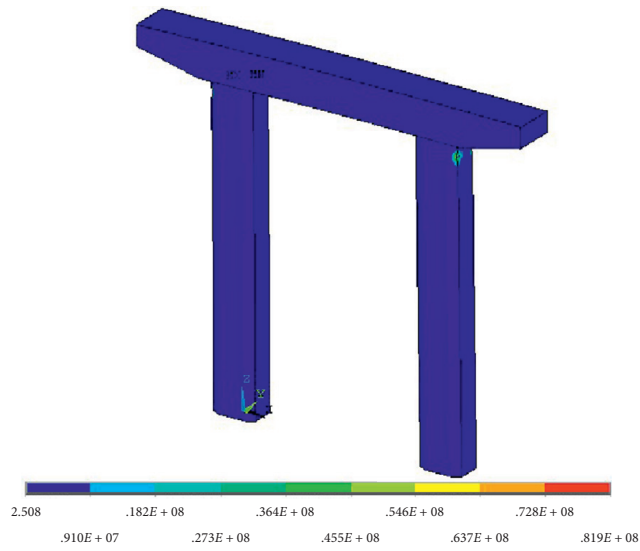

(c)

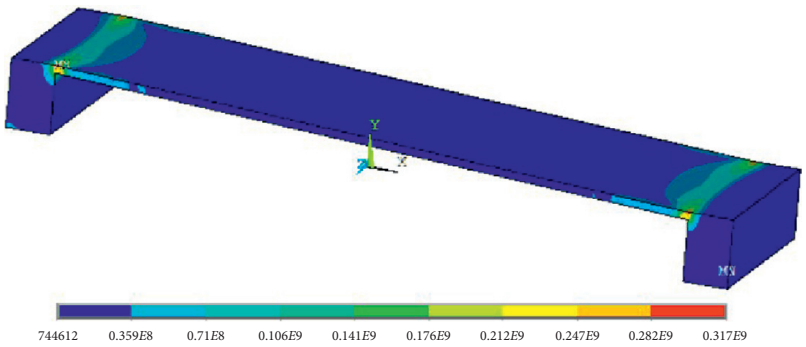

(b)

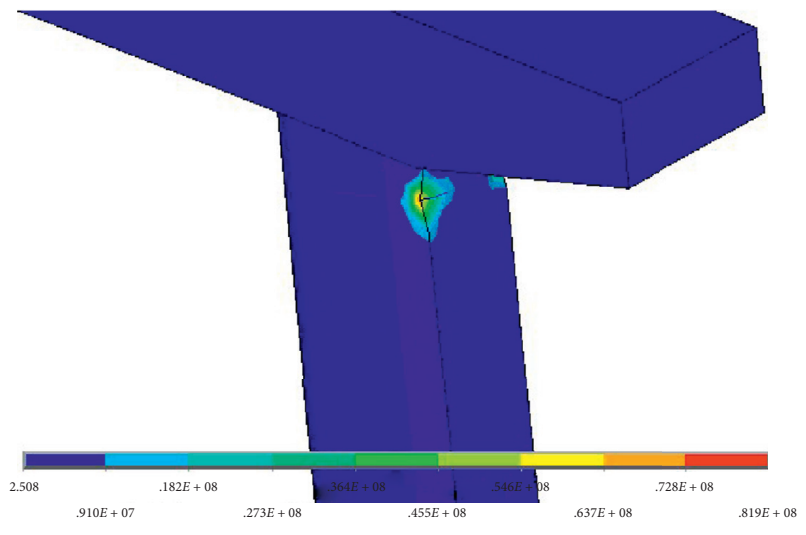

(d)

Figure 17: Von Mises equivalent stress distributions on the main girder section and the piers for the emergency rescue cases (unit: Pa). (a) Repair scheme 1 (the main girder section). (b) Repair scheme 2 (the main girder section). (c) Whole view of piers in repair scheme 1. (d) Enlarged view of a pier in repair scheme 1. 


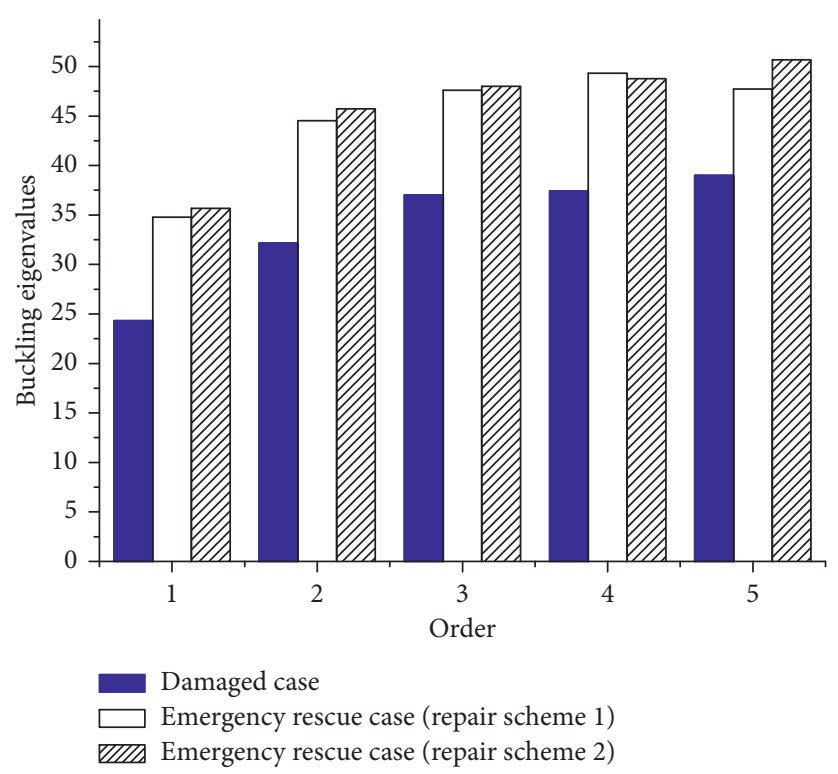

FIgURE $18: 1^{\text {st }} \sim 5^{\text {th }}$ buckling eigenvalues calculated for different cases.

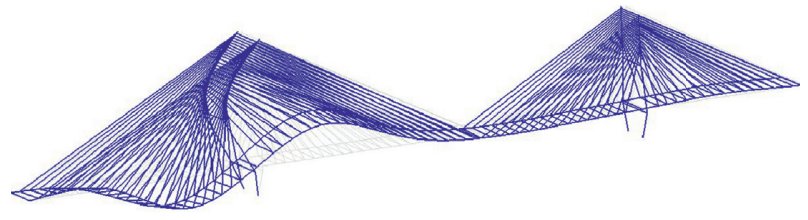

(a)

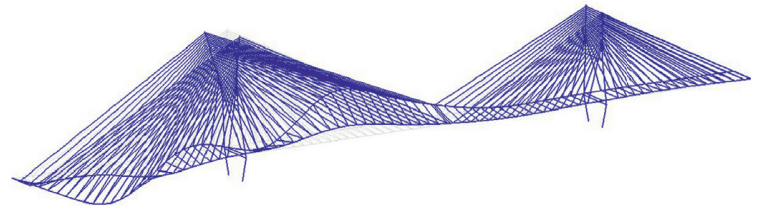

(c)

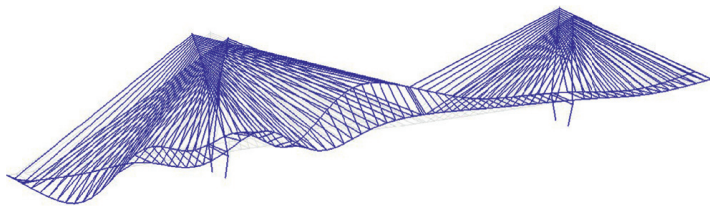

(e)

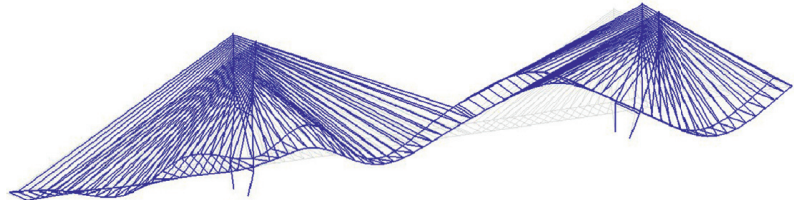

(g)

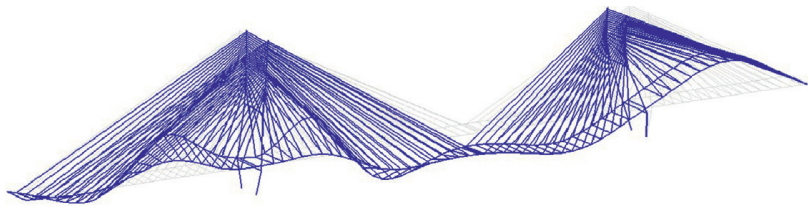

(i)

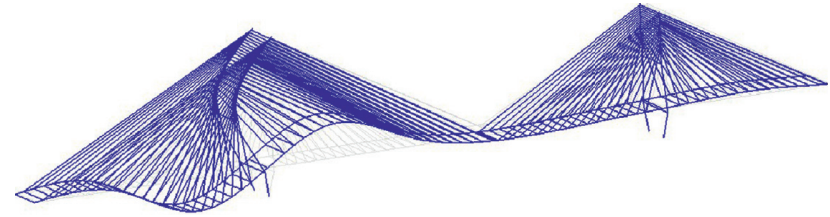

(b)

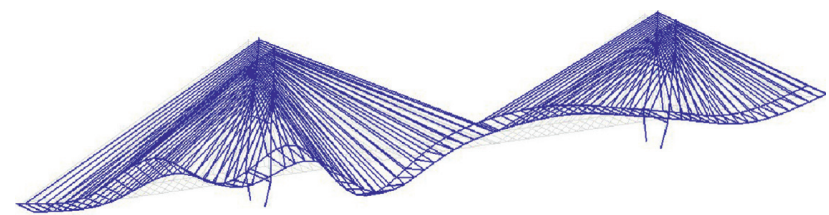

(d)

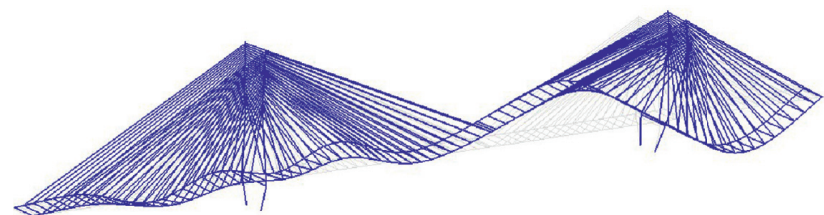

(f)

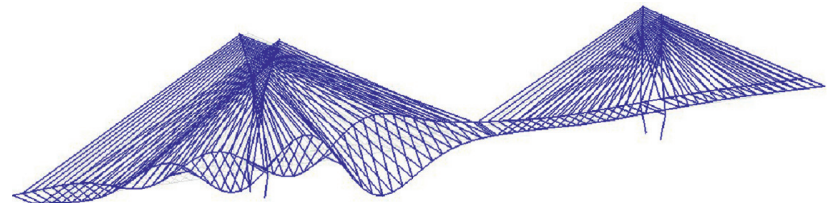

(h)

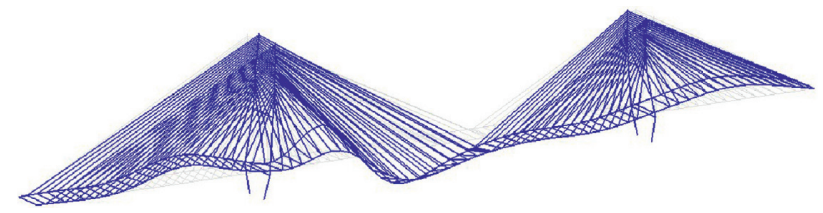

(j)

FIGURE 19: Low-order instability shapes for different cases. (a) $1^{\text {st }}$ order for damaged case. (b) $1^{\text {st }}$ order for emergency rescue case (repair scheme 2). (c) $2^{\text {nd }}$ order for damaged case. (d) $2^{\text {nd }}$ order for emergency rescue case (repair scheme 2). (e) $3^{\text {rd }}$ order for damaged case. (f) $3^{\text {rd }}$ order for emergency rescue case (repair scheme 2). (g) $4^{\text {th }}$ order for damaged case. (h) $4^{\text {th }}$ order for emergency rescue case (repair scheme 2 ). (i) $5^{\text {th }}$ order for damaged case. (j) $5^{\text {th }}$ order for emergency rescue case (repair scheme 2 ). 
models for both repair scheme 1 and repair scheme 2, and the results are shown in Figures 20-23. As shown in Figure 20, the displacement responses calculated for the two repair cases are close, and they are also close to the displacement response calculated for the intact case (Figure 9(a)). After the repairs, the displacements for the main girder at the auxiliary piers are the same as those for the capping beam of the auxiliary piers. Similar situation holds true for the stress distributions on pylons and the main girder (see Figures 21 and 10(a)). These suggest that the mechanical states of the entire bridge are close to the ideal design state after the repairs, and ideal maintenances can be achieved for both repair schemes. However, after the repairs, the cable force distributions (Figure 22) are different from that for the intact case (Figure 11(a)), suggesting that cable force adjustments are required after the bearing repairs. According to Figure 23, after the repairs, the stress distributes uniformly on the main girder section; no stress concentration is observed, and the maximum von Mises equivalent stress is not greater than the material strength of C55 concrete. These suggest that the local strength failure can be avoided after the repairs.

1.4. Bearing Repair Undertaken on the Location. Based on the numerical investigations of the repair processes, both of the two repair schemes are proved to be effective in solving the strength and the stiffness problems with the damaged Poyanghu Bridge. However, in view of the feasibility, the repair cost, and the local behaviors of the piers in the emergency rescue cases, the repair personnel finally chose to repair the bearings according to repair scheme 2 .

During September to October in 2019, repair scheme 2 was successfully implemented on the location by practicing engineers. Four steps were actually undertaken during the repair process with details shown in Table 1 . According to Table 1, the displacements of the main girder and the forces of the stayed cables near the auxiliary piers were monitored during the whole repair process, which guaranteed the safety of the structure during the repair process and the quality of repair.

1.5. Repair Monitoring on the Location. According to Ref. [14], the forces in stayed cables measured on the cable-stayed bridges can be employed to calculate the real-time elevations of the main girders and detect the uncertain parameters of the structures. Therefore, different from the traditional monitoring practice of the beam bridges, the present repair monitoring of Poyanghu Cable-stayed Bridge not only measures the displacements of the main girder but the forces of the stayed cables as well. Special attention is focused on information extraction and utilization from the monitored forces of the stayed cables. As shown in Figure 24 and Table 1, the forces in six stayed cables above the auxiliary piers on both the upstream side (1\# 3\# cables) and the downstream side $\left(1^{\prime} \# \sim 3^{\prime} \#\right.$ cables) are monitored during repair steps $1-3$ by arranging one accelerometer on each of the six stayed cables.
Using the Fourier transform and peak-picking method, the fundamental frequencies of the monitored stayed cables are identified from the one-min-long transverse acceleration samples measured continuously using the accelerometers arranged. Then, using the cable force formula, the continuous forces of the stayed cables are calculated from the fundamental frequencies. Figures 25(a) and 25(b) show two continuous force samples of the $1 \#$ stayed cable measured in repair steps 1 and 2, respectively. As can be seen in Figure 25, the measured force time-histories of the 1\# stayed cable vary in small intervals, and they are much smaller than the allowable and the ultimate cable forces, suggesting that the mechanical states of the structure are stable and safe in different scenarios; the time-varying mean values of the measured cable forces calculated by using empirical mode decomposition are constants, suggesting that the measured cable forces do not have the gradual changing trends; the mean values of the measured cable forces are close to the FE analysis results (the relative errors between them are kept within $\pm 15 \%$ ), suggesting that the safety of the structure during the repair process and the quality of repair are good. Similar situation holds true for 1\# stayed cable in other repair steps or other cables in different scenarios.

According to Ref. [14], if the horizontal displacements of the pylons are not taken into account, the following equation can be used to calculate the real-time elevations of the main girder:

$$
\Delta u=\frac{\left(F_{2}-F_{1}\right) L}{E A \sin \alpha},
$$

in which $E$ is the elastic modulus of the stayed cable; $A$ is the cross-sectional area of the stayed cable; $\alpha$ is the included angle of the stayed cable and the main girder; $L$ is the length of the stayed cable in its initial state; $F_{1}$ and $F_{2}$ are the cable forces in times 1 and 2, respectively; and $\Delta u$ is the vertical displacement of the main girder from time 1 to time 2 at the cable anchorage. Using equation (1), the real-time elevations of the main girder at the anchorage of $2 \#$ stayed cable are calculated for repair steps 1 3 (Figure 26). According to Figure 26, the real-time elevation varies in the interval [-300 $\mathrm{mm}, 100 \mathrm{~mm}]$ for repair step 1 , and it varies in the interval $[-300 \mathrm{~mm}, 0 \mathrm{~mm}]$ for repair steps 2 and 3, suggesting that the overall stiffness of the structure is strengthened, and the mechanical state of the structure is gradually stabilized with the process of the bearing repair.

1.6. Safety Assessment of the Repaired Poyanghu Bridge. During the repair, the repair personnel arranged a rubber cushion of $56 \mathrm{~mm}$ thickness between each bearing and the main girder. Therefore, the vertical stiffness of the bearings has been changed and should be regarded as a noticeable uncertain parameter. For the safety assessment of the repaired Poyanghu Bridge to take place, a truthful FE model with the bearings of the accurate vertical stiffness should be employed. Since the forces measured in stayed cables can be used to identify the uncertain parameters with the bridge [14], this portion of study updates the simplified beam 


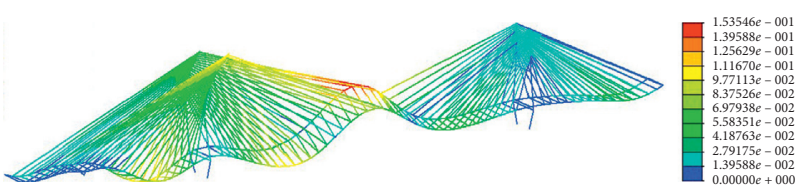

(a)

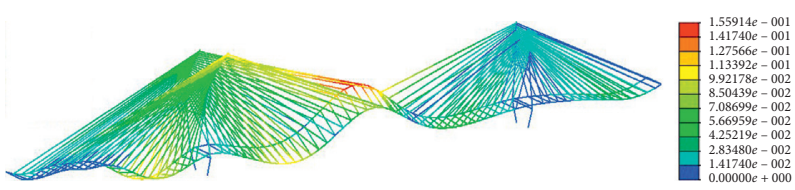

(b)

Figure 20: Displacement responses for the repair cases (unit: m): (a) repair scheme 1 and (b) repair scheme 2.

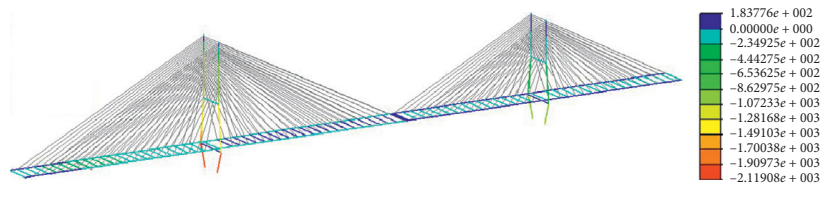

(a)

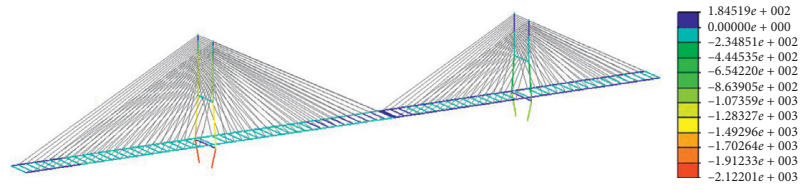

(b)

FIGURE 21: Stress distributions on pylons and the main girder for the repair cases (unit: tonf $/ \mathrm{m}^{2}$ ): (a) repair scheme 1 and (b) repair scheme 2.

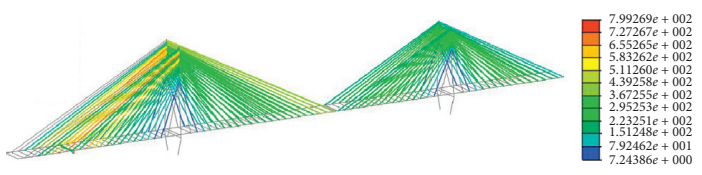

(a)

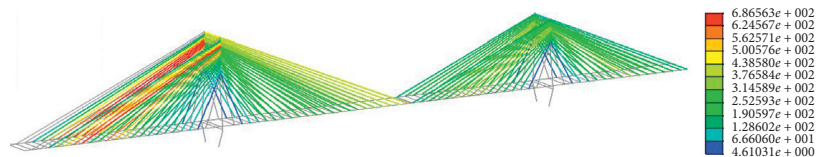

(b)

FIgURE 22: Cable force distributions for the repair cases (unit: tonf): (a) repair scheme 1 and (b) repair scheme 2.

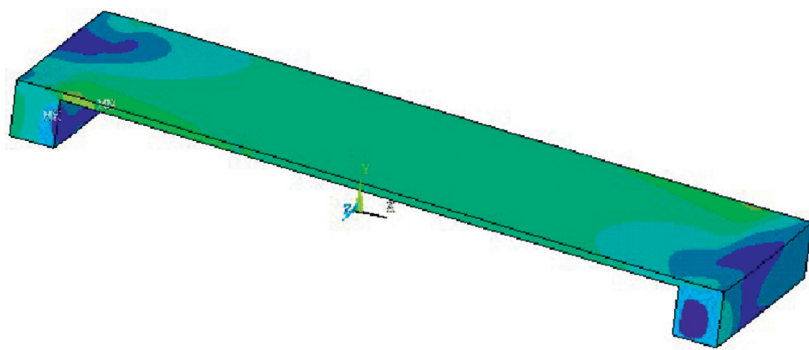

$\begin{array}{llllllllll}110059 & 0.145 E 7 & 0.278 E 7 & 0.412 E 7 & 0.545 E 7 & 0.679 E 7 & 0.813 E 7 & 0.946 E 7 & 0.108 E 8 & 0.121 E 8\end{array}$

(a)

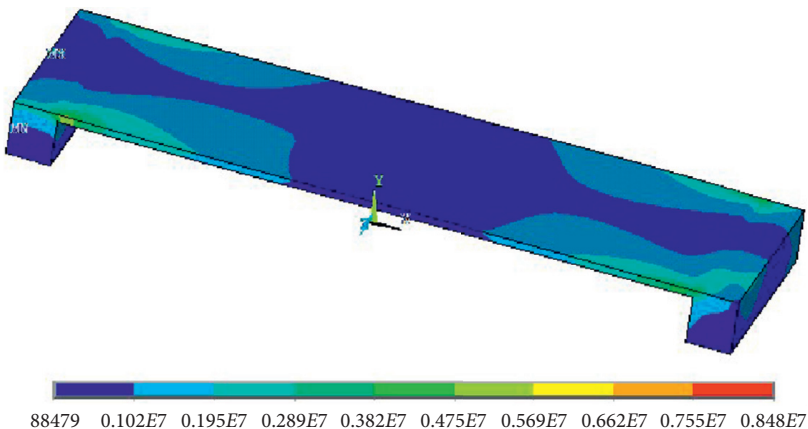

(b)

FIGURE 23: Von Mises equivalent stress distributions on the main girder section for the repair cases (unit: Pa): (a) repair scheme 1 and (b) repair scheme 2 .

element model of the entire bridge based on the measured cable forces before the safety assessment.

\subsubsection{Model Updating of the Simplified Beam Element Model.} The model updating of the simplified beam element model is undertaken by a meta-model-based parameter identification method [15]. First, the vertical stiffness of the downstream side bearing above the auxiliary piers is regarded as the uncertain parameter, and the FE model established for the repair case of repair scheme 2 is used for sampling based on single-factor experimental design. After the sampling, the cable forces of $1 \# \sim 3 \#$ cables are obtained at five sample points (Table 2).

Second, the regression models are established for the cable forces of $1 \# \sim 3 \#$ stayed cables using data listed in Table 2. The regression model established for the cable force of 2\# stayed cable is formulated as follows:

$$
F_{2 \#}=3.773 e 6+55.56 e-10^{*} \mathrm{~A} \text {, }
$$

in which $F_{2 \#}$ is the cable force in 2\# stayed cable and $A$ is the vertical stiffness of the bearing. With regard to the established models, $F$ value tests suggest that the regression models are significant and the lack-of-fit terms are 
TABLE 1: Details of repair process and monitoring practices.

\begin{tabular}{|c|c|c|c|c|c|}
\hline Step & Time & $\begin{array}{l}\text { Location of the } \\
\text { repaired bearing }\end{array}$ & Specific works & $\begin{array}{l}\text { Monitored displacement } \\
\text { directions }\end{array}$ & $\begin{array}{l}\text { Monitored } \\
\text { cables }\end{array}$ \\
\hline 1 & $\begin{array}{c}19 \sim 20 \\
\text { September }\end{array}$ & Downstream side & Establish temporary supports & $\begin{array}{l}\text { Longitudinal, transverse, } \\
\text { and vertical directions }\end{array}$ & $\begin{array}{l}1 \# \sim 3 \#, \\
1^{\prime} \# \sim 3^{\prime} \#\end{array}$ \\
\hline 2 & $\begin{array}{c}25 \\
\text { September }\end{array}$ & Downstream side & $\begin{array}{c}\text { Remove temporary supports, apply heavy vehicles, } \\
\text { and tension anchoring bolts arranged between } \\
\text { main girder and bearings }\end{array}$ & $\begin{array}{c}\text { Longitudinal, transverse, } \\
\text { and vertical directions }\end{array}$ & $\begin{array}{l}1 \# \sim 3 \#, \\
1^{\prime} \# \sim 3^{\prime} \#\end{array}$ \\
\hline 3 & $\begin{array}{l}12 \sim 24 \\
\text { October }\end{array}$ & Upstream side & $\begin{array}{c}\text { Remove the damaged anchoring bolts and ream } \\
\text { holes }\end{array}$ & $\begin{array}{l}\text { Longitudinal, transverse, } \\
\text { and vertical directions }\end{array}$ & 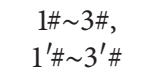 \\
\hline 4 & 25 October & Upstream side & $\begin{array}{l}\text { Apply heavy vehicles and tension anchoring bolts } \\
\text { arranged between the main girder and the bearings }\end{array}$ & $\begin{array}{l}\text { Longitudinal, transverse, } \\
\text { and vertical directions }\end{array}$ & \\
\hline
\end{tabular}

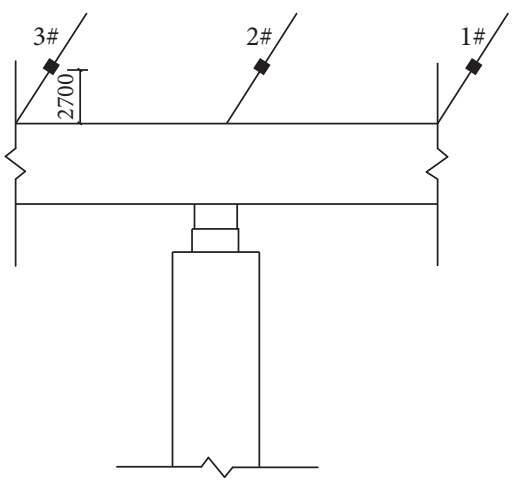

(a)

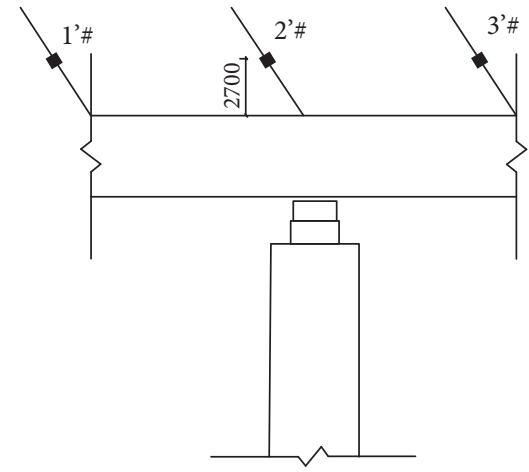

(b)

FIGURE 24: Monitored stayed cables above auxiliary piers with accelerometers arranged (unit: mm): (a) upstream side and (b) downstream side.

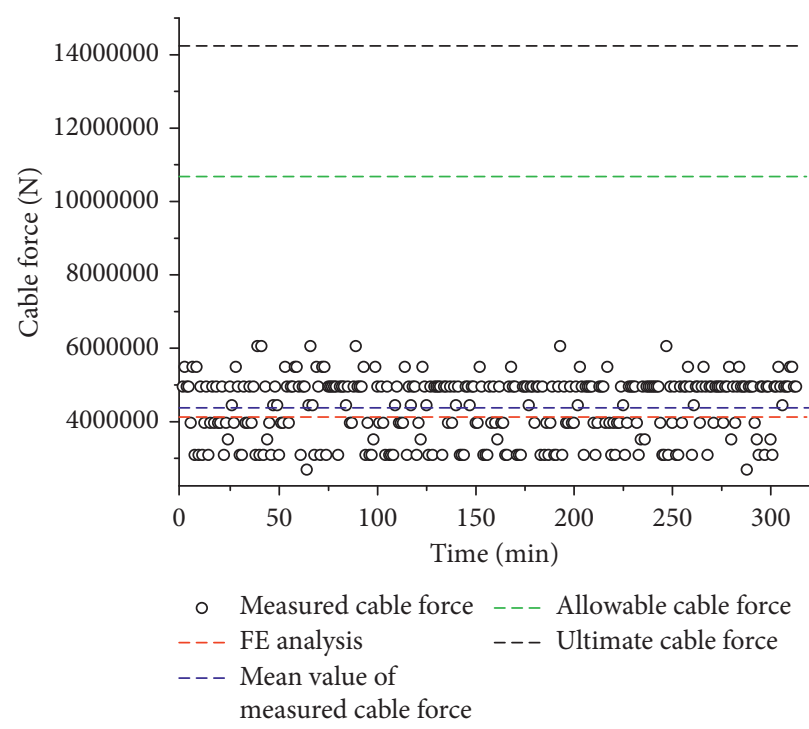

(a)

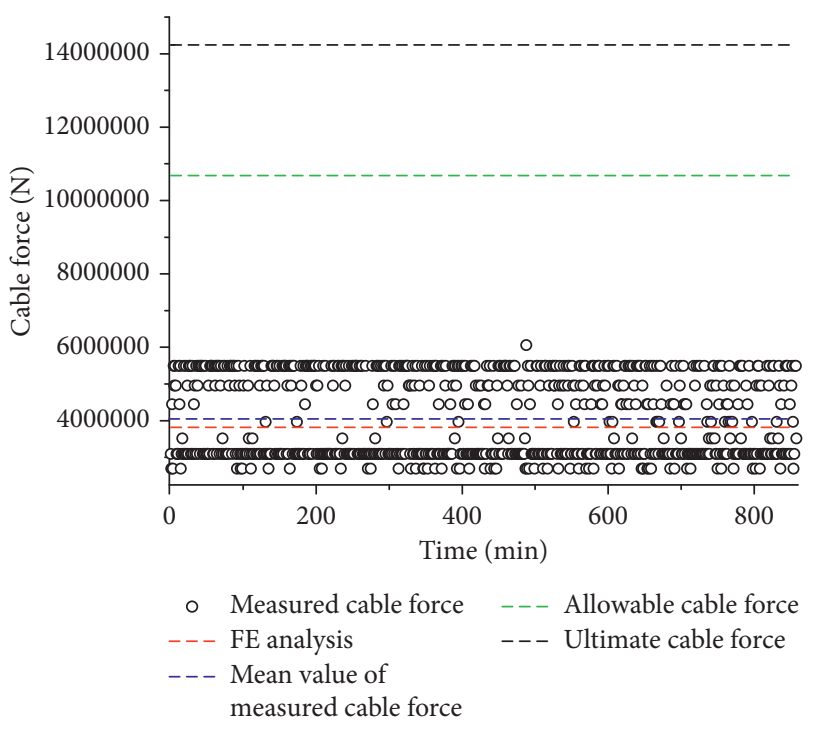

(b)

Figure 25: Continuous cable force samples of the 1\# stayed cable. (a) Sample measured on 18 September (repair step 1). (b) Sample measured on 25 September (repair step 2).

insignificant; $R^{2}$ tests suggest that the models are accurate and the experimental errors are small; adequate precision (i.e., signal-to-noise ratio) tests suggest that the signals are sufficient and the fittings are valid over the entire design spaces. These all suggest that the regression models established can replace the FE model for model updating. 


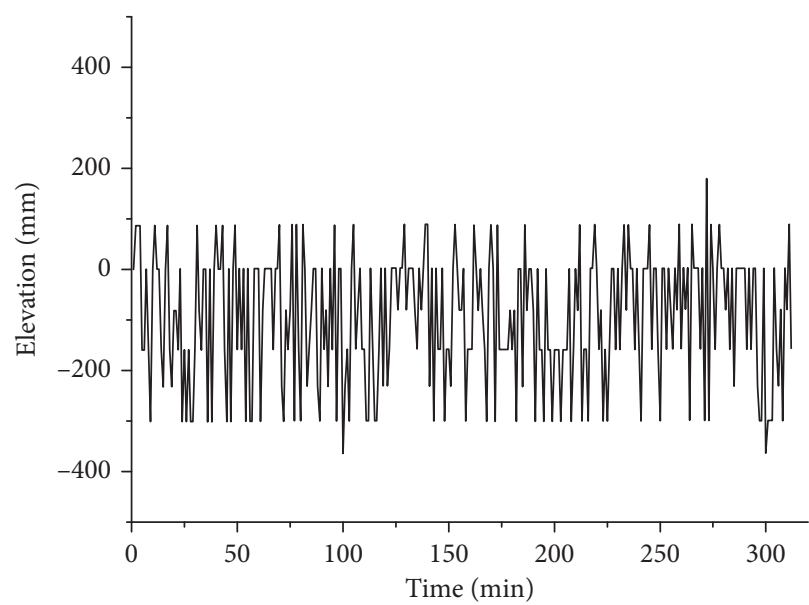

(a)

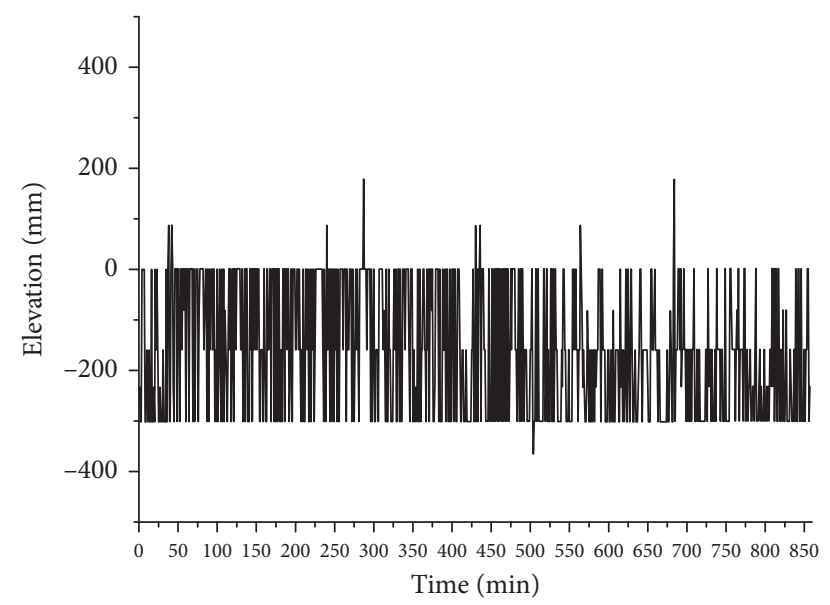

(b)

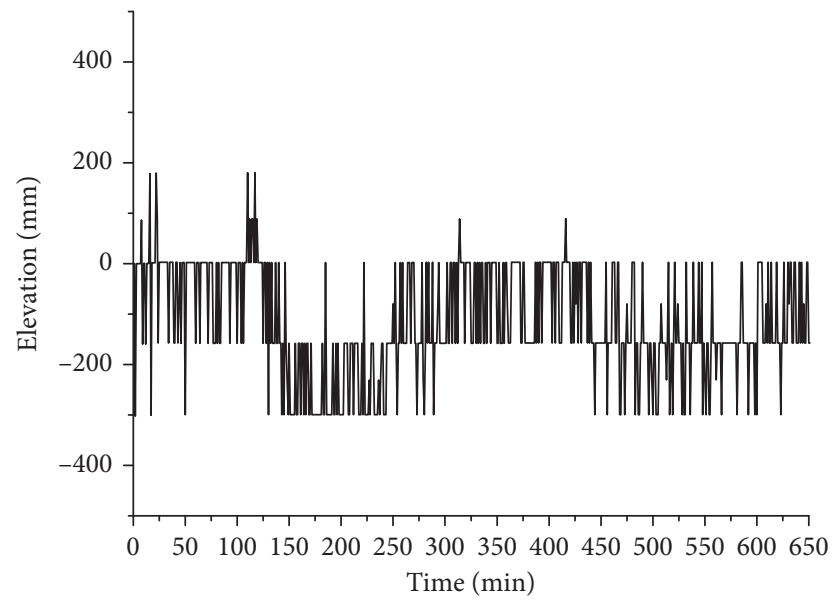

(c)

Figure 26: Real-time elevations of the main girder at the anchorage of 2\# stayed cable. (a) Sample calculated for repair step 1. (b) Sample calculated for repair step 2. (c) Sample calculated for repair step 3.

TABLE 2: Sampling results using the FE model based on single-factor experimental design.

\begin{tabular}{lcccc}
\hline $\begin{array}{l}\text { Sampling } \\
\text { number }\end{array}$ & $\begin{array}{c}\text { Vertical stiffness of the } \\
\text { bearing } A(\mathrm{~N} / \mathrm{m})\end{array}$ & $\begin{array}{c}\text { Cable force in 1\# stayed } \\
\text { cable } F_{1 \#}(\mathrm{~N})\end{array}$ & $\begin{array}{c}\text { Cable force in 2\# stayed } \\
\text { cable } F_{2 \#}(\mathrm{~N})\end{array}$ & $\begin{array}{c}\text { Cable force in 3\# stayed } \\
\text { cable } F_{3 \#}(\mathrm{~N})\end{array}$ \\
\hline 1 & $1 E+011$ & $381.22 e 4$ & $377.27 e 4$ & $405.36 e 4$ \\
2 & $1.5 E+011$ & $381.22 e 4$ & $377.27 e 4$ & $405.36 e 4$ \\
3 & $2 E+011$ & $381.22 e 4$ & $377.28 e 4$ & $405.36 e 4$ \\
4 & $2.5 E+011$ & $381.23 e 4$ & $377.28 e 4$ & $405.36 e 4$ \\
5 & $3 E+011$ & $381.23 e 4$ & $377.28 e 4$ & $405.36 e 4$ \\
\hline
\end{tabular}

Finally, optimization is undertaken using the regression models established treating the mean values of the cable forces measured on the location as the optimization targets, and vertical stiffness of the repaired bearing is identified as $299999682617 \mathrm{~N} / \mathrm{m}$.

1.6.2. Safety Assessment Using the Updated Model. Using the updated FE model of Poyanghu Bridge, the eventual mechanical state of the repaired structure under the dead loads is calculated and shown in Figures 27-29. According to Figure 27, after repair, the bridge deck is smooth under the dead loads; the maximum displacement (around $0.15 \mathrm{~m}$ ) is at the center of the main span. According to Figure 28, after repair, no stress concentration can be observed on the pylons and the main girder of the bridge; the maximum stress on the pylons and the main girder is not greater than the material strength of C55 concrete. According to Figure 29, after repair, the cable force distribution is slightly different from the ideal design state. 


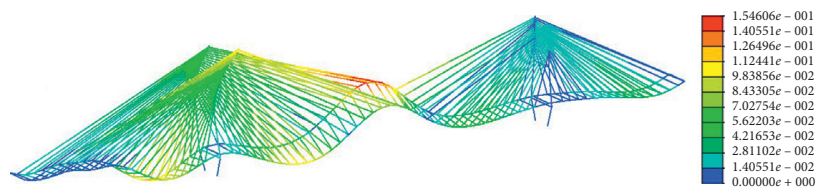

Figure 27: Structural displacement after repair (unit: m).

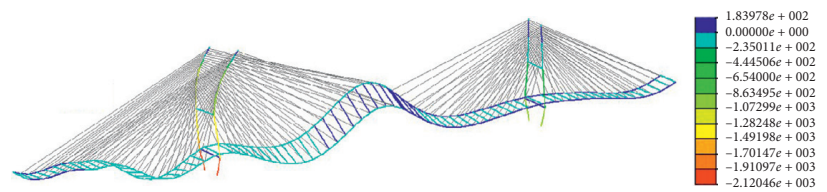

FIgURE 28: Stress distribution on pylons and the main girder after repair (unit: tonf $/ \mathrm{m}^{2}$ ).

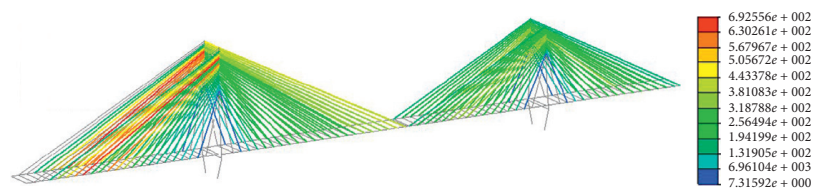

Figure 29: Cable force distribution after repair (unit: tonf).

\section{Conclusions}

The main findings of this study concerning bearing repair and monitoring for Poyanghu Cable-stayed Bridge are summarized below:

(1) Safety assessments of the cable-stayed bridges with damaged bearings have rarely been undertaken by the engineering community in the history. According to the present numerical analyses, the static mechanical state of the Poyanghu Bridge with damaged bearings unfavorably deviates from the ideal design state. Besides, the dynamic properties of the bridge change due to the damage, possibly leading to amplified dynamic structural responses under strong winds. Therefore, the damaged bearings of this and other similar cable-stayed bridges should be repaired in time to quickly restore the safety and the serviceability of the entire structures.

(2) Two innovative bearing repair schemes for cablestayed bridges have been proposed. According to numerical analyses, the mechanical states of Poyanghu Bridge during the repair processes are similar for the two proposed repair schemes, and both repair schemes can basically guarantee the safety of the structure during the repair process and the quality of repair. However, with the concerns of the feasibility, the economy, and the local behaviors of the piers in the emergency rescue case, repair scheme 2 is superior to repair scheme 1 . The practicing engineers finally repaired the bearings of Poyanghu Bridge according to repair scheme 2 .

(3) Different from the traditional repair monitoring practice for the beam bridges which focuses on the displacements of the main girder, more attention should be paid to the forces of the stayed cables for the repair monitoring of cable-stayed bridges. The monitoring results for Poyanghu Bridge suggest that the safety of the structure during the repair process and the quality of repair are good. Moreover, the monitoring data are employed to update the numerical model of Poyanghu Bridge. Using the updated numerical model, the safety and serviceability of Poyanghu Bridge after the repair are assessed. The assessment indicates that the safety and the serviceability of the repaired Poyanghu Bridge are good overall; but, the cable force distribution might be different from the design values, and related adjustments are required in the next stage.

\section{Data Availability}

The data supporting the results of this study are available from the corresponding author (e-mail: g.wu@seu.edu.cn) upon request.

\section{Conflicts of Interest}

The authors declare that they have no conflicts of interest regarding the publication of this article.

\section{Acknowledgments}

The authors gratefully thank the financial supports from the National Natural Science Foundation of China (grant no. 51908124) and the China Postdoctoral Science Foundation (grant no. 2016M601793). 


\section{References}

[1] Q. Han and J. Wang, "Brief analysis of construction technology of bridge bearing for urban rail transit," Journal of Beijing University of Civil Engineering and Architecture, vol. 31, no. 1, pp. 42-46, 2015, in Chinese.

[2] H. Liu, H. Li, and M. Guang, "Study on repair and replacement of tension and compression steel bearing for steel truss girder," Construction Technology, vol. 44, no. 17, pp. 42-46, 2015, in Chinese.

[3] Y. Wu and J. Song, "Bridge bearing replacement numerical simulation and optimization analysis method," Construction Technology, vol. 42, no. S, pp. 351-353, 2013, in Chinese.

[4] M. Aria and R. Akbari, "Inspection, condition evaluation and replacement of elastomeric bearings in road bridges," Structure and Infrastructure Engineering, vol. 9, no. 9, pp. 918-934, 2013.

[5] S. Maalek, R. Akbari, and S. Ziaei-Rad, "The effects of the repair operations and replacement of the elastomeric bearings on the modal characteristics of a highway bridge," Structure and Infrastructure Engineering, vol. 6, no. 6, pp. 753-765, 2010.

[6] B. Atmaca, T. Dede, and M. Grzywinski, "Optimization of cables size and prestressing force for a single pylon cablestayed bridge with Jaya algorithm," Steel and Composite Structures, vol. 34, no. 6, pp. 853-862, 2020.

[7] B. Atmaca and S. Ates, "Determination of bearing type effect on elastomeric bearing selection with SREI-CAD," Advances in Computational Design, vol. 2, no. 1, pp. 43-56, 2017.

[8] B. Atmaca and S. Ates, "Construction stage analysis of threedimensional cable-stayed bridges," Steel \& Composite Structures, vol. 12, no. 5, pp. 413-426, 2012.

[9] F. Fabbrocino, M. Modano, I. Farina, G. Carpentieri, and F. Fraternali, "Optimal prestress design of composite cablestayed bridges," Composite Structures, vol. 169, no. SI, pp. 167-172, 2017.

[10] F. Ferreira and L. Simões, "Optimum design of a cable-stayed steel footbridge with three dimensional modelling and control devices," Engineering Structures, vol. 180, pp. 510-523, 2019.

[11] A. M. B. Martins, L. M. C. Simões, and J. H. J. O. Negrão, "Cable stretching force optimization of concrete cable-stayed bridges including construction stages and time-dependent effects," Structural and Multidisciplinary Optimization, vol. 51, no. 3, pp. 757-772, 2015.

[12] J. J. Jorquera-Lucerga, J. A. Lozano-Galant, and J. Turmo, "Structural behavior of non-symmetrical steel cable-stayed bridges," Steel and Composite Structures, vol. 20, no. 2, pp. 447-468, 2016.

[13] S. Hou and G. Wu, "A low-cost IoT-based wireless sensor system for bridge displacement monitoring," Smart Materials and Structures, vol. 28, no. 8, p. 16, Article ID 085047, 2019.

[14] C. Huang, "Real-time elevation measurement and damage detection of cable-stayed bridge based on the change of the cable force," M. Sc Dissertation, Guangzhou University, Guangzhou, China, 2016, in Chinese.

[15] X. Cheng, J. Dong, X. Han, and Q. Fei, "Structural health monitoring-oriented finite-element model for a large transmission tower," International Journal of Civil Engineering, vol. 16, no. 1, pp. 79-92, 2018. 